\title{
Effects of sex on the incidence and prognosis of spinal meningiomas: a Surveillance, Epidemiology, and End Results study
}

\author{
Harrison J. Westwick, MD, MSc, ${ }^{1}$ and Mohammed F. Shamji, MD, PhD, FRCSC 2,3 \\ 'Department of Surgery, Division of Neurosurgery, Centre Hospitalier de l'Université de Montréal, Hôpital Notre-Dame, Montreal, \\ Quebec; ${ }^{2}$ Toronto Western Hospital, Division of Neurosurgery; and ${ }^{3}$ Department of Surgery, University of Toronto, Toronto, \\ Ontario, Canada
}

OBJECT Most spinal meningiomas are intradural lesions in the thoracic spine that present with both local pain and myelopathy. By using the large prospective Surveillance, Epidemiology, and End Results (SEER) database, the authors studied the incidence of spinal meningiomas and examined demographic and treatment factors predictive of death.

METHODS Using SEER*Stat software, the authors queried the SEER database for cases of spinal meningioma between 2000 and 2010. From the results, tumor incidence and demographic statistics were computed; incidence was analyzed as a function of tumor location, pathology, age, sex, and malignancy code. Survival was analyzed by using a Cox proportional hazards ratio in SPSS for age, sex, marital status, primary site, size quartile, treatment modality, and malignancy code. In this analysis, significance was set at a $p$ value of 0.05 .

RESULTS The 1709 spinal meningiomas reported in the SEER database represented $30.7 \%$ of all primary intradural spinal tumors and $7.9 \%$ of all meningiomas. These meningiomas occurred at an age-adjusted incidence of $0.193(95 \%$ Cl 0.183-0.202) per 100,000 population and were closely related to sex (337 [19.7\%] male patients and 1372 [80.3\%] female patients). The Cox hazard function for mortality in males was higher (2.4 [95\% Cl 1.7-3.5]) and statistically significant, despite the lower lesion incidence in males. All-cause survival was lowest in patients older than 80 years. Primary site and treatment modality were not significant predictors of mortality.

CONCLUSIONS Spinal meningiomas represent a significant fraction of all primary intradural spinal tumors and of all meningiomas. The results of this study establish the association of lesion incidence and survival with sex, with a less frequent incidence in but greater mortality among males.

http://thejns.org/doi/abs/10.3171/2014.12.SPINE14974

KEY WORDS SEER; spinal meningioma; incidence; radiation; surgery; oncology

$\mathrm{M}$ ENINGIOMAS are among the most common primary intradural spinal tumors, arising predominantly in the thoracic spine. They present in patients most frequently with both local pain and motor dysfunction, although a median of $38.5 \%$ (range $4 \%-61 \%$ ) of patients will have an identifiable degree of sphincter dysfunction upon detection. ${ }^{4,5,7,8,12,14-16,18-20,22}$ When neurologically symptomatic, these lesions normally require surgical resection because slow growth in the confined spinal canal most frequently leads to thoracic myelopathy. Serial observation and stereotactic radiosurgery have been im- plemented for incidental lesions, although the durability and adverse effects of such management have not yet been established. 2,4,5, ,15,16

Although these lesions are seen frequently in clinical practice, little has been established about their epidemiology beyond what can be drawn from the more conventional cranial literature. The objective of this study was to define the incidence, demographic associations, prognosis, and epidemiology of spinal meningiomas through use of the Surveillance, Epidemiology, and End Results (SEER) database. 


\section{Methods}

\section{SEER Database}

We used the SEER database, which draws from cancer registries for 18 regions of the United States and encompasses $26 \%$ of the total population. The data we investigated spanned the period from 2000 to 2010. Cases were selected from the SEER database on the basis of a microscopically confirmed diagnosis and a location of the spinal cord (International Classification of Diseases, 9th edition code C72.0), spinal meninges (C70.1), or cauda equina (C72.1), with recoding based on histology results of meningioma, benign, or malignant. The data were obtained in accordance with SEER database policies.

The overall incidence was compared with the total incidence of all spinal tumors and the total incidence of all meningiomas. Survival was defined as the time from diagnosis to death from any cause. Hazards ratios were calculated with the Cox model.

\section{Statistical Analysis}

Statistical analysis was performed using SEER*Stat 8.1.2. We calculated $95 \%$ CIs with a 2000 census age-adjusted standard US population by using the Tiwari method, with a $p$ value of 0.05 set as significant.

IBM SPSS version 21 statistical software was used for Cox analysis with $95 \%$ CIs, a 0.05 entry, a 0.10 removal, and a maximum of 20 iterations with all variables being analyzed. The trend of incidence was computed by using the curve-fit function with a $\mathrm{p}$ value of 0.05 set as significant using incidence calculated for each age group; the 0to 5-year-old age group was excluded, because there were no applicable data available in the SEER database.

\section{Results}

\section{Incidence of Spinal Meningiomas}

The incidence of spinal meningiomas was calculated in the SEER database as a function of sex, age, and malignancy. There were 1709 cases identified in the SEER database, which represents an age-adjusted incidence of 0.193 per 100,000 population (95\% CI $0.183-0.202$ per $100,000)$. This population was based on census data for the US population for the time period of 2000-2010, which reflects a total population of 906,398,023. The numbers of cases, percentages of meningiomas, and incidence rates with 95\% CIs are shown in Table 1.

A statistically significant difference was identified in the incidence of spinal meningiomas in males and females $(\mathrm{p}<0.05)$. The incidence in males was 0.083 per 100,000 (95\% CI 0.074-0.092 per 100,000), whereas the incidence in females was 0.286 per 100,000 (95\% CI $0.271-0.302$ per 100,000) (337 [19.7\%] male patients and 1372 [80.3\%] female patients).

The 75- to 79-year-old group had the highest incidence of spinal meningioma (0.887 per 100,000 [95\% CI 0.763-1.025 per 100,000$])$. In the SEER*Stat calculation of incidence, there were no age groups with a significant difference in incidence (Table 1). Incidence is shown plotted as a function of age (with $95 \%$ confidence intervals) in Fig. 1. There were no identified spinal meningiomas in the 0 - to 5-year-old age group. The trend of incidence as a
TABLE 1. Summary statistics of spinal meningiomas in the SEER database

\begin{tabular}{|c|c|c|}
\hline Variable of Interest & No. of Cases (\%) & $\begin{array}{l}\text { Incidence Rate }(95 \% \mathrm{Cl}) \\
\quad(\text { per } 100,000)^{*}\end{array}$ \\
\hline \multicolumn{3}{|l|}{ Sex } \\
\hline Grouped, M \& F & 1709 (reference) & $0.193(0.183-0.202)$ \\
\hline M & $337(19.7)$ & $0.083(0.074-0.092)$ \\
\hline $\mathrm{F}$ & $1372(80.3)$ & $0.286(0.271-0.302) \dagger$ \\
\hline \multicolumn{3}{|l|}{ Age (yrs) } \\
\hline $0-5$ & 0 & NA \\
\hline $5-9$ & $3(0.18)$ & $0.005(0.001-0.014)$ \\
\hline $10-14$ & $7(0.4)$ & $0.011(0.004-0.022)$ \\
\hline $15-19$ & $15(0.9)$ & $0.023(0.012-0.037)$ \\
\hline $20-24$ & $17(1.0)$ & $0.027(0.015-0.042)$ \\
\hline $25-29$ & $21(1.2)$ & $0.033(0.021-0.051)$ \\
\hline $30-34$ & $34(2.0)$ & $0.053(0.037-0.075)$ \\
\hline $35-39$ & $49(2.9)$ & $0.073(0.054-0.097)$ \\
\hline $40-44$ & $95(5.6)$ & $0.138(0.112-0.169)$ \\
\hline $45-49$ & $123(7.2)$ & $0.183(0.152-0.219)$ \\
\hline $50-54$ & $158(9.2)$ & $0.261(0.222-0.305)$ \\
\hline $55-69$ & $205(12.0)$ & $0.407(0.353-0.466)$ \\
\hline $60-64$ & $183(10.7)$ & $0.470(0.404-0.543)$ \\
\hline $65-69$ & $179(10.5)$ & $0.599(0.515-0.694)$ \\
\hline $70-74$ & $195(11.4)$ & $0.793(0.685-0.912)$ \\
\hline $75-79$ & $184(10.8)$ & $0.887(0.763-1.025)$ \\
\hline $80-84$ & $172(10.1)$ & $1.108(0.949-1.286)$ \\
\hline$>85$ & $69(4.0)$ & $0.51(0.397-0.645)$ \\
\hline
\end{tabular}

$\mathrm{NA}=$ not available.

* Age-adjusted incidence rates $(95 \% \mathrm{Cls})$ for a standard US population in 2000.

† Statistical significance at a $p$ value of $<0.05$ (male vs female; white vs black; benign vs malignant or borderline behavior).

function of age was found to be exponential $\left(\mathrm{R}^{2}=0.935 ; \mathrm{p}\right.$ $<0.005 ; \mathrm{F}=216$ ).

The majority of patients in this cohort had tumors exhibiting benign characteristics; 1641 (96.0\%) were benign, with an age-adjusted incidence of 0.185 per $100,000(95 \%$ CI 0.176-0.194 per 100,000). The incidence of both borderline (35 [2.0\%]) and malignant (33 [1.9\%]) tumors was 0.004 per 100,000 (95\% CI $0.003-0.005$ per 100,000$)$. While these incidences are different $(\mathrm{p}<0.05)$, the low number of malignant tumors precluded meaningful conclusions and these were not included in further analysis.

\section{Annual Percentage Change for Spinal Meningiomas}

Age-related incidence of spinal meningiomas is shown in Fig. 1. The overall population exhibited an incidence that was higher among females than males, and the annualized increases in incidence were higher for the female population (4.6\% [95\% CI $-8.6 \%$ to $19.4 \%]$ ) than in the overall population (3.7\% [95\% CI $-9.3 \%$ to $18.4 \%])$.

\section{Meningioma Incidence and Spinal Tumors}

There were 5564 primary intradural spinal tumors in the SEER database, with an age-adjusted incidence rate 


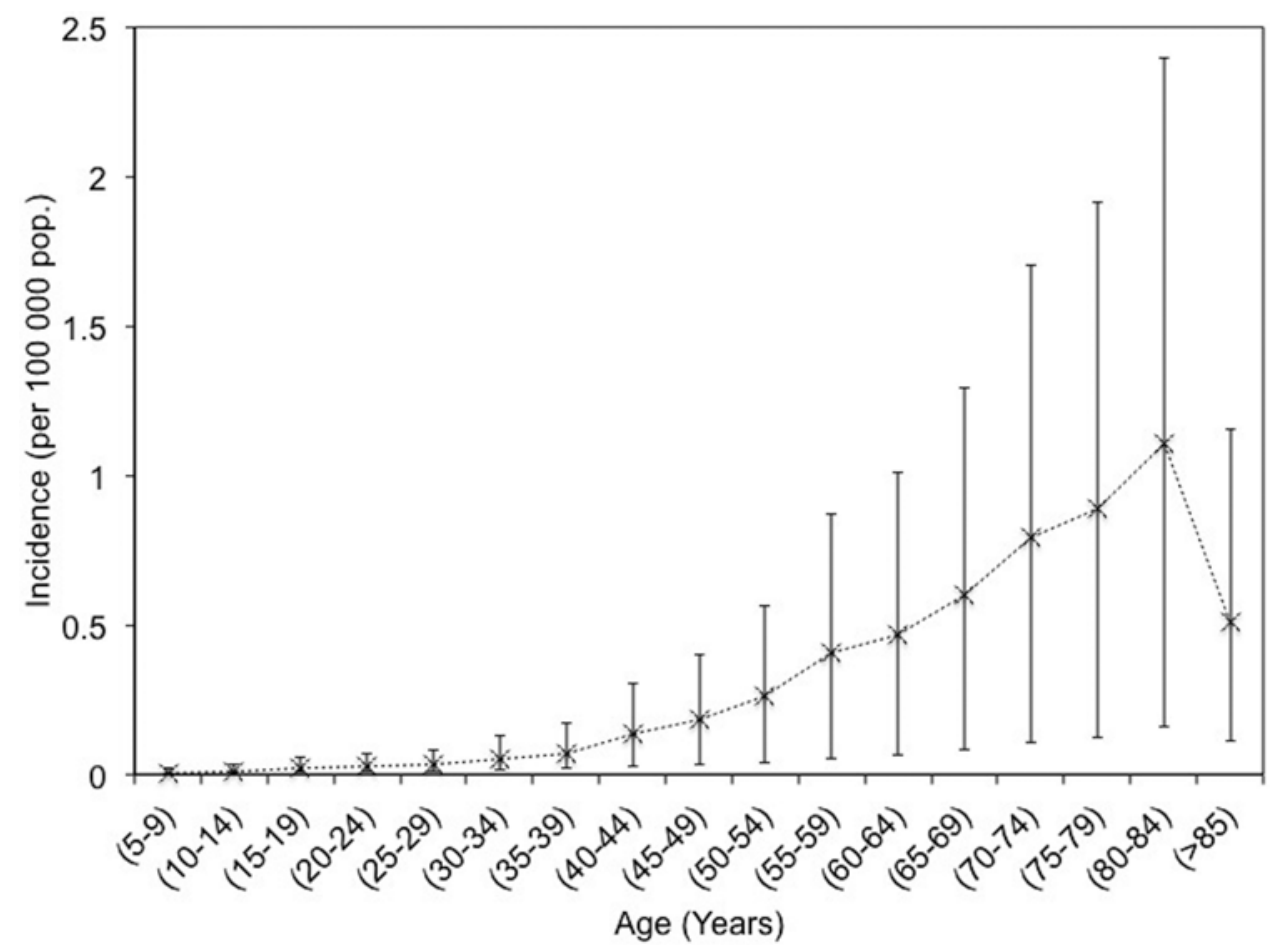

FIG. 1. Spinal meningioma incidence as a function of age (note the exponential relationship). Error bars reflect the $95 \%$ Cls.

of 0.616 per 100,000 (95\% CI $0.600-0.633$ per 100,000$)$. There were 25 histological tumor types, of which meningiomas were the most frequent, representing 30.7\% of primary intradural spinal tumors (1709 of 5564) and an age-adjusted incidence of 0.193 per 100,000 (95\% CI $0.183-0.202$ per 100,000$)$. Ependymoma was the next most frequent tumor pathology (18.2\%), followed by nerve sheath tumors $(15.5 \%)$ and ependymoma variants (10.3\%).

\section{Spinal and Intracerebral Meningiomas}

A total of 21,655 cases of meningioma (including intracranial and extracranial locations) were extracted from the SEER database between 2000 and 2010, representing a total incidence in the age-adjusted population of 2.408 per 100,000 (95\% CI $2.376-2.44$ per 100,000). The majority of meningiomas are located in the cranial compartment, but 1709 (7.9\%) patients had spinal lesions. This cohort formed the study group for this work.

\section{Meningioma Survival Distribution}

Cox proportional hazard ratios were computed to evaluate patient survival, with the variables age, sex, marital status, primary site, size quartile, treatment, and tumor behavior. These results are listed in Table 2. There was a lower incidence among males, although the hazard ratio for males compared with females was 2.4 (95\% CI 1.7-3.5, $\mathrm{p}<0.01$, Fig. 2). An age of $>80$ years was the reference value with the lowest overall survival, and there were statistically significantly lower hazard ratios in all other age groups.

\section{Meningioma Treatment}

Hazard ratios for treatment of spinal meningiomas stratified by treatment are also listed in Table 2 . Treatment was broken down into the categories of surgery alone (1613 cases), surgery with radiotherapy (26 cases), radiotherapy alone (3 cases), no treatment (62 cases), and unknown (5 cases). Despite the minority of cases treated with radiotherapy alone, there was a nonsignificant trend for radiotherapy alone exhibiting the poorest outcomes (hazard ratio 10.6 [95\% CI 0.8-133.5]; $\mathrm{p}=0.068$ ).

\section{Discussion}

Previous SEER database studies of intracranial meningiomas and tumors of the spine have been conducted, adding to the literature a range of epidemiological data related to these tumors. ${ }^{1,21}$ These studies examined demographic factors, incidence, and outcomes with various treatment modalities. Although histopathologically similar to their intracranial counterparts, tumors with a pathoanatomical location within the spine can complicate resection. Meningioma is the most common intradural primary spinal neoplasm, 5,6 as confirmed by the 1709 meningiomas (30.7\%) of 5564 spinal tumors we found in the SEER database (age-adjusted incidence 0.193 per 100,000 [95\% CI $0.183-0.202$ per 100,000$])$. In addition, of all meningiomas in the SEER database, the location was coded as the spine for 1709 of 21,655 cases, corresponding to $7.9 \%$ of the cases. This ratio corresponds with those in smaller studies in the literature, in which the spine accounted for $8 \%-12 \%$ of the locations. ${ }^{5,10,20}$

Of the demographic factors examined, the difference in incidence between the sexes was found to be significant; a higher frequency among females by 3:1 to $4: 1$ has been well described ${ }^{5,10}$ and was confirmed in this nationwide cohort study with a female-to-male ratio of $3.5: 1$. The dis- 
TABLE 2. Cox proportional hazard ratios and $p$ values for demographic and treatment factors for spinal meningiomas

\begin{tabular}{|c|c|c|c|}
\hline Variable & No. of Cases (\%) & Hazard Ratio (95\% Cl) & p Value \\
\hline \multicolumn{4}{|l|}{ Age (yrs) } \\
\hline$<20$ & $25(1.5)$ & $0.123(0.015-1.001)^{*}$ & $0.05^{*}$ \\
\hline $20-39$ & $121(7.1)$ & $0.14(0.053-0.37)^{\star}$ & $<0.05^{*}$ \\
\hline $40-59$ & $581(33.9)$ & $0.129(0.076-0.219)^{*}$ & $<0.05^{\star}$ \\
\hline $60-79$ & $741(43.4)$ & $0.356(0.247-0.51)^{*}$ & $<0.05^{*}$ \\
\hline$>80$ & $241(14.1)$ & 1 (reference) & \\
\hline \multicolumn{4}{|l|}{ Sex } \\
\hline M & $337(19.7)$ & $2.424(1.665-3.53)^{*}$ & $<0.05^{*}$ \\
\hline $\mathrm{F}$ & $1372(80.3)$ & 1 (reference) & \\
\hline \multicolumn{4}{|l|}{ Marital status } \\
\hline Single & $253(14.8)$ & $0.725(0.285-1.843)$ & 0.5 \\
\hline Married & $920(53.8)$ & $0.633(0.287-1.4)$ & 0.3 \\
\hline Widowed/divorced/separated & $456(26.7)$ & $1.131(0.51-2.506)$ & 0.8 \\
\hline Unknown & $80(4.7)$ & 1 (reference) & \\
\hline \multicolumn{4}{|l|}{ Primary site (ICD-9 code) } \\
\hline Spinal meninges (C70.1) & $1659(97.1)$ & NS & NS \\
\hline Spinal cord (C72.0) & $48(2.8)$ & NS & NS \\
\hline Cauda equina (C72.1) & $2(0.1)$ & 1 (reference) & \\
\hline \multicolumn{4}{|l|}{ Size quartile (mm) } \\
\hline$<14$ & $228(13.3)$ & $1.11(0.67-1.836)$ & 0.686 \\
\hline 14-19 & $225(13.2)$ & $1.662(1.045-2.643)^{*}$ & $0.032^{*}$ \\
\hline $19.1-24$ & $217(12.7)$ & $1.168(0.715-1.909)$ & 0.535 \\
\hline$>24$ & $201(11.8)$ & $1.321(0.767-2.273)$ & 0.315 \\
\hline Unknown & $838(49.0)$ & 1 (reference) & \\
\hline \multicolumn{4}{|l|}{ Treatment } \\
\hline Surgery alone & $1613(94.4)$ & $0.986(0.113-8.628)$ & 0.99 \\
\hline Radiation \& surgery & $26(1.5)$ & $2.678(0.266-27.0)$ & 0.404 \\
\hline Radiation alone & $3(0.2)$ & $10.6(0.841-133.5)$ & 0.068 \\
\hline No treatment & $62(3.6)$ & $1.602(0.164-15.6)$ & 0.685 \\
\hline Unknown & $5(0.3)$ & 1 (reference) & \\
\hline \multicolumn{4}{|l|}{ Tumor behavior } \\
\hline Benign & $1641(96.0)$ & $0.627(0.275-1.427)$ & 0.266 \\
\hline Borderline malignancy & $35(2.0)$ & $0.532(0.126-2.44)$ & 0.39 \\
\hline Malignant & $33(1.9)$ & 1 (reference) & \\
\hline
\end{tabular}

ICD-9 = International Classification of Diseases, 9th edition; NS = nonsignificant.

* Statistically significant.

crepancy in incidence between the sexes has, in the case of intracranial meningiomas, been attributed to hormonal effects in women. ${ }^{23,24} \mathrm{~A}$ tendency toward incidence later in life has been described, and in the present study, there was an exponential trend of incidence with respect to age. . $^{8,17,18}$ These tumors were most frequently benign ( $96 \%$ of cases), supporting the known epidemiology of these lesions, with more advanced staging being much less common..$^{18}$

Survival distributions were calculated for various predictive factors; age, sex, marital status, primary site, size quartile, treatment modality, and malignant character were considered. The factors that had statistically significant hazard ratios for mortality according to the Cox model were age, sex, and size quartile. When compared with females, males had a hazard ratio of 2.424 (95\% CI
1.665-3.53), and this difference was significant. The median ages of the male and female patients were 59 and 64 years, respectively. This difference is all the more important given the significantly lower incidence in males. An age of $>80$ years was statistically significant compared with all other age groups; however, this was the oldest age grouping, and death from all causes was considered. This result is understandably limited because of the natural life expectancy and survival above the age of 80 years; however, age was identified as an important prognostic factor for poor outcome in several studies. ${ }^{11,17}$ Sandalcioglu et al. ${ }^{17}$ described a series of 131 surgical patients, of whom 126 exhibited neurological stability or improvement, 1 died as a result of a perioperative myocardial infarction, and 4 experienced neurological deterioration. All 4 of these 


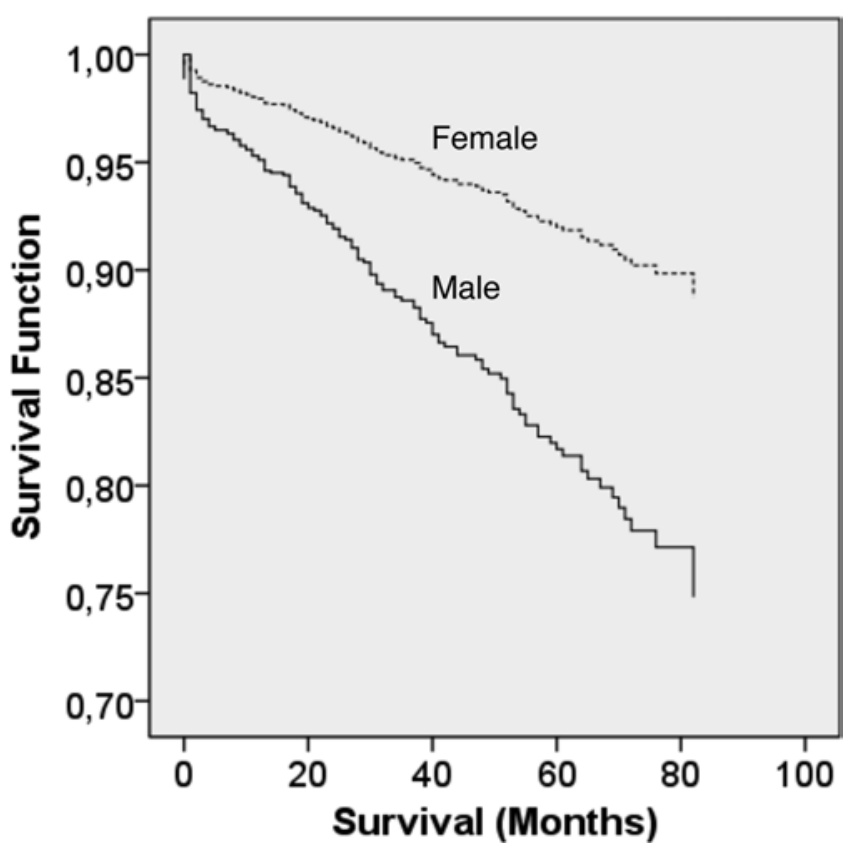

FIG. 2. Cox survival function stratified according to sex. Note the lower survival rate with respect to time with males. This difference is statistically significant, as calculated in the Cox model.

patients were $>70$ years old, and most of them had significant tumoral calcification and a preoperative Frankel grade of C. Morandi et al. ${ }^{11}$ operated on 30 elderly patients aged $>70$ years; all the patients survived and exhibited neurological stability or improvement at the 12-month follow-up, and the all-cause mortality rate was $25 \%$ at a mean follow-up time of 62 months. These results suggest the safety and efficacy of surgical intervention for such pathology in elderly patients who are otherwise good surgical candidates. Tumor-size quartile was also predictive of survival; the second quartile (14-19 $\mathrm{mm}$ ) had the highest hazard ratio for survival, although this result may be a statistical aberration. The differences in mortality rates with respect to benign versus malignant status were not significant in this work, potentially because of the heterogeneity in diagnostic and treatment modalities, although other studies have suggested lesser survival among patients with higher-grade lesions. ${ }^{18}$

Radiotherapy for meningiomas is occasionally initiated without histological confirmation or for cases in which various factors render biopsy or excision impossible, and unfortunately, these cases were not considered in this study; this mostly affects the results for the outcomes of the radiotherapy-alone group. Such a modality is implemented when surgical treatment is contraindicated ${ }^{15}$ or as an adjunct to resection of a malignant or progressively enlarging benign lesion. ${ }^{3,9,16}$ In this SEER study, it is unclear if the patients who received radiotherapy alone received this treatment because of extensive disease or because they were medically complicated and not candidates for surgical resection.

This type of database study has clear limitations; however, with knowledge of the limitations, results can provide an insight into the demographics and outcomes of spinal meningiomas. Despite the large sample size, representing
$26 \%$ of the US population, the SEER database was not designed specifically for the study of spinal meningiomas. In this study, the primary outcome variable was mortality; however, we were unable to consider other important secondary variables, such as neurological status (preoperative and postoperative), functional status, medical comorbidities, complications, specifics of the operative procedure, and length of hospital stay. ${ }^{13}$ These factors, often more than mortality alone, are considered carefully when proposing the surgical resection of a meningioma to a patient. Such characteristics are especially important, given that the goal of surgery is to preserve neurological function rather than to confer a survival advantage Other factors that affect postoperative neurological status include preoperative status, $, 1,17,19$ infiltration and invasion of tumor with the spinal cord, $4,16,18,19$ calcification of the tumor, $8,12,16$ and anterior dural attachment, ${ }^{8,12,16}$ among other factors.

Although limitations exist, this type of database enables the study of large population groups and provides a sufficient number of patients for a relatively uncommon condition. SEER database studies also enable interpretations of incidence and treatment while eliminating singleinstitution selection bias or limitations from small case series. Furthermore, ours was a prospective database study, which limited the effects of patients having been removed for missing data. ${ }^{13}$

\section{Conclusions}

The SEER database provided insight into spinal meningioma incidence and associated mortality. Among the 1709 cases of spinal meningioma in the SEER database, incidence was found to depend on age and sex and was more frequent with advancing age and among the female population. Mortality was also affected by sex, with shorter survival among males, but was unaffected by primary tumor site or treatment administered. The results of this work can help guide surgical management of spinal meningiomas by providing the clinician and patient an estimate of demographic and treatment-related survival.

\section{References}

1. Cahill KS, Claus EB: Treatment and survival of patients with nonmalignant intracranial meningioma: results from the Surveillance, Epidemiology, and End Results Program of the National Cancer Institute. Clinical article. J Neurosurg 115:259-267, 2011

2. Dodd RL, Ryu MR, Kamnerdsupaphon P, Gibbs IC, Chang SD Jr, Adler JR Jr: CyberKnife radiosurgery for benign intradural extramedullary spinal tumors. Neurosurgery 58:674-685, 2006

3. Gerszten PC, Quader M, Novotny J Jr, Flickinger JC: Radiosurgery for benign tumors of the spine: clinical experience and current trends. Technol Cancer Res Treat 11:133-139, 2012

4. Gezen F, Kahraman S, Canakci Z, Bedük A: Review of 36 cases of spinal cord meningioma. Spine 25:727-731, 2000

5. Gottfried ON, Gluf W, Quinones-Hinojosa A, Kan P, Schmidt MH: Spinal meningiomas: surgical management and outcome. Neurosurg Focus 14(6):e2, 2003

6. Helseth A, Mørk SJ: Primary intraspinal neoplasms in Norway, 1955 to 1986 . A population-based survey of 467 patients. J Neurosurg 71:842-845, 1989

7. King AT, Sharr MM, Gullan RW, Bartlett JR: Spinal meningiomas: a 20-year review. Br J Neurosurg 12:521-526, 1998 
8. Levy WJ Jr, Bay J, Dohn D: Spinal cord meningioma. J Neurosurg 57:804-812, 1982

9. Marchetti M, De Martin E, Milanesi I, Fariselli L: Intradural extramedullary benign spinal lesions radiosurgery. Mediumto long-term results from a single institution experience. Acta Neurochir (Wien) 155:1215-1222, 2013

10. Mirimanoff RO, Dosoretz DE, Linggood RM, Ojemann RG, Martuza RL: Meningioma: analysis of recurrence and progression following neurosurgical resection. J Neurosurg 62:18-24, 1985

11. Morandi X, Haegelen C, Riffaud L, Amlashi S, Adn M, Brassier G: Results in the operative treatment of elderly patients with spinal meningiomas. Spine 29:2191-2194, 2004

12. Namer IJ, Pamir MN, Benli K, Saglam S, Erbengi A: Spinal meningiomas. Neurochirurgia (Stuttg) 30:11-15, 1987

13. Ngwenya LB, Chiocca EA: Editorial: meningioma and radiotherapy. J Neurosurg 117:666-668, 2012

14. Peker S, Cerçi A, Ozgen S, Isik N, Kalelioglu M, Pamir MN: Spinal meningiomas: evaluation of 41 patients. J Neurosurg Sci 49:7-11, 2005

15. Riad H, Knafo S, Segnarbieux F, Lonjon N: Spinal meningiomas: surgical outcome and literature review. Neurochirurgie 59:30-34, 2013

16. Roux FX, Nataf F, Pinaudeau M, Borne G, Devaux B, Meder JF: Intraspinal meningiomas: review of 54 cases with discussion of poor prognosis factors and modern therapeutic management. Surg Neurol 46:458-464, 1996

17. Sandalcioglu IE, Hunold A, Müller O, Bassiouni H, Stolke D, Asgari S: Spinal meningiomas: critical review of 131 surgically treated patients. Eur Spine J 17:1035-1041, 2008

18. Schaller B: Spinal meningioma: relationship between histological subtypes and surgical outcome? J Neurooncol 75:157-161, 2005
19. Setzer M, Vatter H, Marquardt G, Seifert V, Vrionis FD: Management of spinal meningiomas: surgical results and a review of the literature. Neurosurg Focus 23(4):E14, 2007

20. Solero CL, Fornari M, Giombini S, Lasio G, Oliveri G, Cimino C, et al: Spinal meningiomas: review of 174 operated cases. Neurosurgery 25:153-160, 1989

21. Stessin AM, Schwartz A, Judanin G, Pannullo SC, Boockvar JA, Schwartz TH, et al: Does adjuvant external-beam radiotherapy improve outcomes for nonbenign meningiomas? A Surveillance, Epidemiology, and End Results (SEER)-based analysis. J Neurosurg 117:669-675, 2012

22. Subačiutė J: Spinal meningioma surgery: predictive factors of outcome. Acta Medica Lithuania 17:133-136, 2010

23. Vadivelu S, Sharer L, Schulder M: Regression of multiple intracranial meningiomas after cessation of long-term progesterone agonist therapy. J Neurosurg 112:920-924, 2010

24. Wiemels J, Wrensch M, Claus EB: Epidemiology and etiology of meningioma. J Neurooncol 99:307-314, 2010

\section{Author Contributions}

Conception and design: both authors. Acquisition of data: Westwick. Analysis and interpretation of data: both authors. Drafting the article: both authors. Critically revising the article: both authors. Reviewed submitted version of manuscript: both authors. Approved the final version of the manuscript on behalf of both authors: Shamji. Statistical analysis: both authors. Study supervision: Shamji.

\section{Correspondence}

Mohammed F. Shamji, Toronto Western Hospital, 399 Bathurst St., 4th Fl., West Wing, WW4-446, Toronto, ON M5T 2S8, Canada. email: mohammed.shamji@uhn.ca. 